Disponível em:

http://editora.unoesc.edu.br/index.php/race

RACE, Joaçaba, v. 16, n. 2, p. 655-680, maio/ago. 2017

\title{
REFLEXÕES SOBRE O COMPORTAMENTO ECOLOGICAMENTE CORRETO DO CONSUMIDOR CAPIXABA
}

Reflections on the ecologically conscious consumer behaviour in the State of Espírito Santo

Leandro de Athayde Hemerly

E-mail: hammerli.win@gmail.com

Mestre em Administração pela Fucape Business School de Vitória; Doutorando em Direito e Garantias Fundamentais pela Faculdade de Direito de Vitória; Funcionário concursado do Banco do Brasil S.A.

Marcia Juliana d'Angelo

E-mail: marciadangelo@fucape.br

Doutora e Mestre em Administração de Empresas pela Universidade Presbiteriana Mackenzie; Professora Associada e Coordenadora do Centro de Estudos em Sustentabilidade das Organizações (CESO) na Fucape Business School. Endereço para contato: Avenida Fernando Ferrari, 1358, Boa Vista, 29075-505, Vitória, Espírito Santo, Brasil.

Artigo recebido em 07 de março de 2017. Aceito em 02 de maio de 2017. 
Resumo

Os problemas ambientais têm gerado novas oportunidade de negócios para as organizações, como a preocupação com a consciência ecológica e com o comportamento dos consumidores, que estão mais atentos às questões ambientais e sociais e às suas consequências. Assim, neste estudo quantitativo, a partir de um questionário adaptado da escala de Comportamento do Consumidor Ecologicamente Consciente (Ecologically Conscious Consumer Behavior) (ECCB)), de Straughan e Roberts (1999) e Lages e Vargas Neto (2002), teve-se como objetivo discutir os fatores que podem influenciar a consciência ecológica dos consumidores capixabas no momento em que estão realizando suas compras. Os principais resultados mostram que o novo modelo mental dos consumidores capixabas tem implicado a adoção de um comportamento verde somente para alguns hábitos. E quanto maior a escolaridade e a idade, maior a consciência ecológica dos consumidores. Já a renda não impacta tal comportamento, o que é bom para o Estado do Espírito Santo, que tem disparidades sociais e econômicas.

Palavras-chave: Consumo ecologicamente correto. Marketing verde. Legislação.

\section{Abstract}

Environmental problems have generated new business opportunities for organizations, such as concern for ecological awareness and consumer behaviour, which are more conscious to environmental and social issues, and its consequences. Thus, this quantitative study, from the questionnaire of Ecologically Conscious Consumer Behavior of Straughan and Roberts (1999) and Lages and Vargas Neto (2002), aims to discuss the factors that may influence the ecological consciousness of consumers in the State of Espírito Santo when they are shopping. Findings show that consumers'new mental model of this region has implied in adopting a green behavior only for some habits. In addition, the greater the education degree and age, the greater the ecological awareness of consumers. Income does not affect such behavior, which is good for the State of Espírito Santo, which has social and economic disparities.

Keywords: Ecologically conscious consumer. Green marketing. Legislation.

\section{INTRODUÇÃO}

Os problemas ambientais têm levado as organizações a transformarem tais preocupações em oportunidades de negócios verdes (CHEN, 2013). Alguns problemas incluem as mudanças climáticas, a poluição do ar e da água, a perda da biodiversidade, as práticas agropecuárias predatórias, o aumento das disparidades regionais e da pobreza, a escassez da água, o desmatamento, a desertificação e o empobrecimento do solo, entre outros. As oportunidades envolvem, por exemplo, a preocupação com a consciência e com o comportamento dos consumidores, que, por sua vez, estão mais 
atentos às questões ambientais, sociais e suas consequências (CHEN, 2013; CHEN; LAI; WEN, 2006; LAI; CHENG, 2016; HOEK; ROLING; HOLDSWORTH, 2013; LEONIDOU; LEONIDOU; KVASOVA, 2010; PROTHERO et al., 2011; RETTIE; BURCHELL; RILEY, 2012).

Tal consumidor, considerado verde ou ambientalmente correto ou ainda pró-social, tem consciência social e se sente responsável pela proteção do ambiente (WELLS; PONTING; PEATTIE, 2011). Está preocupado em consumir menos e em adquirir serviço, produto, ideia ou experiência economicamente viáveis, socialmente aceitos e ambientalmente corretos (HOFFMANN; SCHLICHT, 2013; LIN; HSU, 2015; PEATTIE, 2001). Contudo, um maior envolvimento dos consumidores com esses problemas não significa a adoção de um comportamento verde, isto é, a adoção de um processo de compra verde - desde o reconhecimento do problema, necessidade ou desejo, passando pelo consumo e descarte, que atenda aos requisitos anteriormente citados (YOUNG et al., 2010).

Dessa forma, cabe ao marketing verde ou ao marketing sustentável a construção de relações de consumo socioambiental sustentáveis entre consumidores e os ambientes natural e social (BELZ; PEATTIE, 2009), estimulando o comportamento voltado para o consumo responsável - baixo consumo e consumo verde (HOFFMANN; SCHLICHT, 2013). Contudo, as ações de marketing verde, por sua vez, também não têm apresentado resultados efetivos porque não basta apenas desenvolver serviços, produtos, ideias ou experiências verdes, mas também encorajar uma mudança de comportamento, ao transformar o conhecimento gerado em ações práticas e em atitudes que degradam o menos possível o meio ambiente (PEATTIE; PEATTIE, 2009; RETTIE; BURCHELL; RILEY, 2012).

Ademais, os consumidores, por meio de várias iniciativas, como as ações de marketing e mídia em geral, já apresentam um nível aceitável de conhecimento acerca do que é um comportamento de compra sustentável ou não (RETTIE; BURCHELL; RILEY, 2012). Além disso, as pressões da sociedade e da legislação, como o incentivo ao uso de sacolas retornáveis nas compras (Lei Municipal n. 15.374) (SÃO PAULO..., 2011), bem como motivações intrínsecas e extrínsecas ao consumidor, podem influenciar tal comportamento, bem como as atitudes que o orientam (MINTON et al., 2012). Entretanto, é necessário considerar a ambivalência dos consumidores, que experimentam sentimentos e percepções opostos a respeito da adoção de um comportamento verde (CHANG, 2011).

No Brasil, a maioria das pesquisas publicadas sobre a temática marketing verde busca entender a relação entre marketing verde e responsabilidade social e am- 
biental (DALMORO; VENTURINI; PEREIRA, 2009); a relação entre marketing verde e estratégia na visão de empreendedores (VEIGA NETO et al., 2014); e a adoção de práticas socioambientais nas indústrias do Paraná (LOPES; PACAGNAN, 2014). Embora haja diversas pesquisas que abordem comportamentos ambientalmente responsáveis (OLIVEIRA; CORREIA; GÓMEZ, 2014; YEH; LAGE, 2015; SACRAMENTO et al., 2014), o comportamento do consumidor verde deve ser estudado e analisado sob muitos aspectos, dada sua complexidade. Adicionalmente, considerando as dimensões culturais e continentais do Brasil, é relevante conhecer os comportamentos ambientalmente responsáveis em suas diversas regiões e estados, a exemplo de estudos nas Cidades de Porto Alegre (LAGES; VARGAS NETO, 2002) e São Paulo (ENOKI et al., 2008), mas são obras publicadas em seminários, portanto, inacabadas.

Posto isso, neste estudo tem-se o seguinte problema de pesquisa: os consumidores capixabas procuram adquirir produtos e assumir hábitos ambientalmente corretos? Nesse sentido, neste estudo teve-se como objetivo discutir os fatores que podem influenciar a consciência ecológica desses consumidores no momento em que estão realizando suas compras, ou seja, se os consumidores capixabas estão tendo a preocupação em adquirir produtos, serviços, ideias e experiências ambientalmente corretos em consonância com hábitos ambientalmente responsáveis.

Trata-se de um esforço integrante de uma pesquisa crítica das contribuições das experiências de desenvolvimento sustentável no Estado do Espírito Santo que, do ponto de vista teórico, contribui, primeiro, por meio das reflexões desta pesquisa, para o debate sobre as variáveis pesquisadas acerca de comportamento ambientalmente sustentável, tanto em estudos qualitativos quanto em quantitativos. Segundo, para generalizar os resultados e reduzir as limitações do estudo de Straughan e Roberts (1999), já que foi replicado em outro contexto (BENSON; BROWN, 2011; BEHSON, 2005). Sob a perspectiva empírica, fornece informações significativas às empresas referentes às posturas éticas adotadas e ao entendimento dos consumidores quanto ao marketing verde e o que é relevante para eles no momento em que estão processando suas compras. Também fornece informações a respeito da visão dos consumidores quanto à relevância das ações do marketing verde e ao comportamento e consciência ecológicos no momento de realização de compras e adoção de hábitos social e ambientalmente adequados, aos diversos atores sociais envolvidos nesse processo. Em particular, ao Governo do Estado do Espírito Santo para o cumprimento das suas ações estratégicas (ESPÍRITO SANTO..., 2015; 2018). 


\section{MARKETING VERDE - CONCEITOS E DELIMITAÇÕES}

Inicialmente, é relevante destacar que o termo marketing verde (green marketing) tem sido usado de forma intercambiável com outros termos como: marketing ambiental, marketing sustentável, ecomarketing, marketing ecológico, enviropreneurial marketing e marketing de estilos de vida sustentáveis (GARG, 2015; RETTIE; BURCHELL; RILEY, 2012). Nessa pesquisa, esses termos também são utilizados de forma intercambiável.

Para se atingir o resultado de uma sociedade ambientalmente responsável, exigem-se mudanças comportamentais por parte dos diversos atores sociais, em particular, das organizações, dos governos e dos consumidores. Para tanto, esses atores precisam reaprender a lidar com essa nova realidade: ter consciência ecológica e assumir as responsabilidades com o meio ambiente, ou seja, precisam se adequar à dicotomia do atendimento aos seus desejos ilimitados com recursos limitados (GARG, 2015; POLONSKY, 1994; 2011).

Nesse sentido, o marketing verde parte do pressuposto de que os consumidores estão mais conscientes e dispostos a mudarem suas atitudes relacionadas às compras de produtos, serviços, ideias e experiências (ZHAO et al., 2014; HOEK; ROLING; HOLDSWORTH, 2013; PROTHERO et al., 2011; STRAUGHAN; ROBERTS, 1999), havendo, portanto, necessidade de mudanças nas ações de marketing das organizações. Assim, marketing verde consiste no conjunto de transações de tais compras entre empresas, seus clientes e o ambiente natural, para satisfazer necessidades e desejos dos consumidores, causando mínimo impacto ao meio ambiente. Para tanto, as decisões do marketing sustentável têm se baseado nos pilares ambientais e sociais, como justiça social e respeito ao meio ambiente (HUANG; RUST, 2011) e em estratégias para alcançar a sustentabilidade (GARG, 2015; RICHEY JUNIOR et al., 2014). Para apoiar essa discussão, adicionalmente, foram criados novos conceitos, como a satisfação verde, a confiança verde, a lealdade verde e o valor verde, a partir do marketing tradicional, mas voltados para um marketing ecologicamente correto (CHEN, 2013).

Contudo, as ações de marketing verde não têm apresentado resultados efetivos porque não basta apenas desenvolver serviço, produto, ideia ou experiência verdes, são necessárias ações práticas para encorajar uma mudança de comportamento que respeite o meio ambiente (PEATTIE; PEATTIE, 2009; RETTIE; BURCHELL; RILEY, 2012). Nesse contexto, algumas iniciativas do marketing verde envolvem encorajar a mudança para um comportamento verde ao orientar os consumidores a con- 
siderarem algum serviço, produto, ideia ou experiência verde como normal (RETTIE; BURCHELL; BARNHAM, 2014; RETTIE; BURCHELL; RILEY, 2012). Ou estimular atitudes e comportamentos éticos, uma vez que os consumidores estariam dispostos a adquirir e a pagar mais, inclusive, por marcas que respeitem as relações com os ambientes natural e social (HOEK; ROLING; HOLDSWORTH, 2013). Ou, ainda, envolvem comportamentos de conservação e de compra ambientalmente amigáveis e valores como orientação homem-natureza (PAÇO et al., 2013). Adicionalmente, incentivar o comportamento de consumo ecologicamente consciente ou a consciência ecológica do consumidor (STRAUGHAN; ROBERTS, 1999).

\subsection{O COMPORTAMENTO DO CONSUMIDOR ECOLOGICAMENTE CORRETO}

Um consumidor consciente ecologicamente é bem informado e no que se refere ao seu comportamento, preocupa-se em consumir de forma diferente, ou seja, importa-se com o descarte, com o planejamento de suas aquisições, com a diminuição do seu consumo próprio, em reduzir todo tipo de desperdício. Prefere produtos feitos com o uso de tecnologias consideradas limpas e com consumo baixo de energia, além de embalagens recicláveis (DAHLSTROM, 2012; PORTILHO, 2005). Tal consumidor tem consciência ecológica ou ambiental, ou seja, habilidade para entender o meio ambiente no qual está inserido, suas ações perante ele, bem como as consequências das ações ao longo do tempo. Essa referida consciência somente se torna plena quando se desenvolve uma visão sistêmica do meio ambiente, sua casa, seu bairro, sua cidade, seu estado, seu país, seu Planeta (OTTMAN, 2004).

Para autores como Rettie, Burchell e Barnham (2014), tal comportamento sustentável deveria ser considerado normal, enquanto o comportamento insustentável, isto é, a não observância dos fatores discutidos até aqui, deveria ser considerado anormal. E ocorre exatamente o contrário: alguns comportamentos sustentáveis são considerados anormais e os insustentáveis, normais. Por isso, propõem um processo social de normalização social para inverter a percepção desses comportamentos. Por exemplo, o uso de sacolas plásticas era considerado um comportamento normal até a chegada das sacolas recicláveis, que, por sua vez, passaram a ser o novo comportamento normal. Importante ressaltar que o processo social de normalização nem sempre ocorre naturalmente. Em particular, na Cidade de São Paulo, esse processo foi imposto pela Lei Municipal n. 15.374, que "proibiu a distribuição gratuita ou venda de sacolas plásticas a consumidores em todos os estabelecimentos comerciais do mu- 
nicípio.” (SÃO PAULO..., 2011). Logo, houve uma rejeição muito grande por parte de todos os atores sociais envolvidos, dados os conflitos de interesses e as ações judiciais. Somente após o Decreto Municipal n. 55.827 (SÃO PAULO..., 2015) e o fechamento de acordos entre organizações, governo e órgãos de proteção ao consumidor, foi possível deflagrar ações de mudança de hábitos (FUNDAÇÃO PROCON, 2015).

Posto esse exemplo, percebe-se que a preocupação com um maior cuidado com o meio ambiente exige, dentro de outras coisas, ter uma legislação ambiental mais “dura”, para que os investimentos ambientais sejam de fato implementados como uma cultura consciente e responsável. Soma-se à regulamentação a pressão dos consumidores, dos stakeholders e dos investidores, contribuindo para o aumento do grau de consciência ecológica de cada país. Por isso a mudança de paradigma voltada para a consciência ambiental para se pensar de maneira diferente e ter cadeias produtivas mais limpas (DAHLSTROM, 2012).

Embora os consumidores, por meio de várias iniciativas de marketing e da mídia em geral já apresentem um nível aceitável de conhecimento acerca do que é um comportamento de compra sustentável ou não (RETTIE; BURCHELL; RILEY, 2012), a educação é considerada um fator contributivo para fomentar o comportamento do consumidor considerado verde, pois se trata de uma maior conscientização do cliente não apenas quando está realizando suas compras, mas de uma maneira diferente e responsável de agir com o meio ambiente. Não deixar de consumir, mas consumir sabendo que suas ações terão um impacto ecológico. E esses referidos impactos serão sentidos pelas gerações futuras (BUTZKE; PEREIRA; NOEBAUER, 2001).

Dessa forma, para entender melhor o comportamento dos clientes é relevante estudar não somente as consequências comportamentais do consumidor de forma genérica, mas também seus impactos socioculturais em determinada região, se suas escolhas estão direcionadas ao bem coletivo da sociedade. Trata-se, portanto, de uma abordagem holística do marketing (BELK; DHOLAKIA; VENKATESH, 1996). Necessita-se que o cliente esteja consciente de que suas ações - compras, armazenamento e descarte dos produtos - terão impactos positivo ou negativo com o meio ambiente no qual está inserido, portanto, afetando toda a coletividade (COLTRO, 2007).

Algumas pesquisas têm abordado os efeitos da influência pessoal, do conhecimento do consumo verde, das atitudes em relação ao consumo verde e dos moderadores internos e externos no comportamento de consumo ecologicamente consciente (ZHAO et al., 2014). Outras já abarcam ações voltadas para o comportamento do consumidor ambientalmente consciente por meio do entendimento do papel modera- 
dor das percepções de status pró-social na disposição e nas ações reais voltadas a esse comportamento (ZABKAR; HOSTA, 2013).

Diferentemente de escalas anteriores para medir a relação entre o consumo verde e o comportamento dos consumidores verdes que deram muito foco às dimensões demográficas, Straughan e Roberts (1999) propuseram uma escala baseada em critérios psicográficos que descrevem a força relativa das características da sua personalidade, a saber: orientação política, valores altruístas, crenças e atitudes e preocupações com as questões ambientais. O objetivo é entender o comportamento do consumidor verde como: comportamento de consumo ecologicamente consciente, eficácia percebida de consumo (percepção se a compra realizada respeita as demandas ambientais); preocupação ambiental (se o que fazemos como indivíduos faz a diferença); altruísmo (preocupação com o bem-estar dos outros); e liberalismo (crenças políticas de esquerda).

Em particular, o critério comportamento de consumo ecologicamente consciente abrange seis fatores: produto, preocupação do consumidor em adquirir produtos mais pró-sociais e pró-ambientais; reciclagem e reutilização, preocupação em adquirir produtos, serviços, ideias e experiências que, após a submissão a uma série de processos de mudança ou tratamento, possam ser reutilizados; alimentação e saúde, preocupação com a forma como tais produtos, serviços, ideias e experiência têm sido produzidos, aprimorados e propostos; hábitos domésticos, as maneiras mais usuais de lidar e de se comportar ao longo do processo de compra - desde a percepção do problema, o desejo ou a necessidade de adquirir algo até o descarte final (reciclagem, doação, revenda); ações de mudanças, comportamento baseado no conhecimento adquirido e disponível para lidar com a dicotomia consumo desenfreado versus recursos limitados, e ainda, o consumo de energia, agravado pela escassez hídrica, além da falta de investimentos estruturais. Esse conjunto de fatores acarreta sérios problemas para a sociedade organizada (STRAUGHAN; ROBERTS, 1999).

\section{METODOLOGIA}

\subsection{NATUREZA DA PESQUISA E COLETA DE DADOS}

Para cumprir o objetivo que se propôs neste estudo, foi conduzida uma pesquisa quantitativa com corte transversal, uma vez que os dados foram coletados em um ponto único na trajetória dos consumidores (MALHOTRA, 2006; HAIR JUNIOR et al., 2005). Trata-se de um estudo exploratório por se conhecer pouco a respeito des- 
sa temática, em particular no Estado do Espírito Santo (HAIR JUNIOR et al., 2005). No que se refere à população deste estudo, esta abrangeu os consumidores de maneira geral. Já a amostra, não probabilística e por conveniência, incluiu os consumidores capixabas, acessados através da rede social do pesquisador, em razão da facilidade de acesso.

Quanto ao instrumento de coleta de dados, foi aplicado um questionário adaptado da escala de Comportamento do Consumidor Ecologicamente Consciente (Ecologically Conscious Consumer Behavior (ECCB)), de Straughan e Roberts (1999) e Lages e Vargas Neto (2002). Nesse estudo, o objetivo foi discutir somente os fatores que podem influenciar o comportamento ecológico dos consumidores no momento em que estão realizando suas compras. Foram considerados seis fatores do comportamento do consumidor ecologicamente consciente, que representam as variáveis independentes: produto (seis itens); reciclagem e reutilização (cinco itens); hábitos domésticos (quatro itens); ação de mudança (três itens); consumo de energia (dois itens); e alimentação e saúde (quatro itens). Nem todas as variáveis dos estudos de Straughan e Roberts (1999) e Lages e Vargas Neto (2002) foram usadas neste estudo, pois se buscaram somente aquelas que mais se adaptam ao contexto da pesquisa. A variável dependente foi medida pela pergunta: "Eu me considero um consumidor ecologicamente correto?” A mensuração dessas variáveis foi feita por meio de uma escala Likert de cinco pontos, variando de 1 (discordo totalmente) a 5 (concordo totalmente).

Esse questionário, mostrado no Apêndice A, foi complementado com as informações demográficas dos respondentes, como idade, gênero, renda aproximada, escolaridade e local de residência. Como parte da escala de Straughan e Roberts (1999) já havia sido aplicada em outros estudos (ENOKI et al., 2008; LAGES; VARGAS NETO, 2002), não foi aplicado um pré-teste (HAIR JUNIOR et al., 2005) no contexto do Espírito Santo.

Para acesso aos dados, foi realizada uma pesquisa de campo no Estado do Espírito Santo com a distribuição livre de questionários em papel e também por meio do aplicativo gratuito do Google Forms através de e-mail à população-alvo.

\subsection{TRATAMENTO ESTATÍSTICO DOS DADOS}

No que diz respeito ao público-alvo, o presente estudo foi realizado com uma amostra de 375 consumidores. Foi obtido um retorno de 211 questionários respondidos e válidos atendendo aos critérios recomendados por Hair Junior et al. (2005) de pelo menos cinco observações para cada variável independente. Nesse caso, uma razão de 8.44 para cada observação. 
Nessa amostra, em termos de observações atípicas, foram notados dados ausentes. Dessa forma, para não reduzir o tamanho da amostra, foi utilizada a abordagem da estimativa dos dados ausentes por meio da substituição da média (HAIR JUNIOR et al., 2005). Também foi feito o teste de Kolmogorov-Smirnov, que mostrou resultados significativos $(0,000)$ ao nível de $5 \%(<0,05)$ para todas as variáveis, evidenciando o atendimento à suposição da normalidade da amostra.

Com o intuito de usar os fatores utilizados da escala de Comportamento do Consumidor Ecologicamente Consciente Ecologically Conscious Consumer Behavior (ECCB), de Straughan e Roberts (1999) - produto, ação e mudança, consumo de energia, reciclagem e reutilização, alimentação e saúde - foram calculados os escores somados para representar esses mesmos constructos, conforme recomendado por Hair Junior et al. (2005). Em relação às análises estatísticas realizadas, com o objetivo de conhecer e descrever o grupo de entrevistados da amostra, foram utilizadas estatísticas descritivas. Para entender o comportamento das variáveis - produto, reciclagem e reutilização, hábitos domésticos, ação de mudança, alimentação e saúde e consumo de energia - com o objetivo de identificar a existência de relação entre elas foi feita a análise de regressão. E para entender possíveis diferenças entre alguns grupos, em particular quanto às variáveis demográficas, foram feitas análises de diferenças entre as médias - Anova. Todos os cálculos foram feitos com o auxílio do Excel e do software IBM® SPSS, versão 23.

\section{ANÁLISE DOS DADOS}

\subsection{DADOS DEMOGRÁFICOS DA AMOSTRA}

No que se refere ao gênero, 113 respondentes (53,6\%) são do gênero feminino e 98 respondentes (46,4\%) são do gênero masculino. No que diz respeito à idade, verificou-se incidência maior nos entrevistados entre 26 e 35 anos (77), igual a 36,5\% dos entrevistados. E, incidência menor entre 16 e 25 anos (12), equivalendo a 5,7\%. Quanto à escolaridade, apresentou-se um maior número dos respondentes com pós-graduação, compondo 50,2\% deles. A menor incidência de entrevistados (23) equivaleu a 10,9\%, com mestrado/doutorado. Ocorreu certo equilíbrio de respondentes com ensino médio e graduação. Em relação à renda aproximada dos respondentes, apresentou-se equilibrada entre as várias faixas apresentadas. 


\subsection{ESTATÍSTICA DESCRITIVA}

As médias dos fatores consumo de energia, produto e hábitos domésticos, que representam as variáveis independentes mostradas na Tabela 1, são similares e estão acima de 4,0; isso significa que as evidências mostram que os respondentes concordam que esses fatores impactam os seus comportamentos ecologicamente conscientes no momento de realização das compras e quanto aos seus hábitos domésticos. Já os fatores ações de mudança, alimentação e saúde e reciclagem e reutilização apresentaram média acima de 3,0, ou seja, as evidências mostram que os respondentes estão neutros - nem discordam nem concordam - que esses fatores impactam os seus comportamentos ecologicamente conscientes quanto à tomada de decisão no momento de realização das compras, porém, com movimento de tendência a concordarem com tais fatores.

Tabela 1 - Estatística descritiva

\begin{tabular}{lcr}
\hline \multicolumn{1}{c}{$\mathbf{N}=\mathbf{2 1 1}$} & Média & Desvio padrão \\
\hline Consumo de energia & 4,2938 & 0,82168 \\
Produto & 4,1201 & 0,76812 \\
Hábitos domésticos & 4,0948 & 0,68480 \\
Ação de mudança & 3,9763 & 0,88549 \\
Alimentação e saúde & 3,8869 & 0,55976 \\
Reciclagem e reutilização & 3,4919 & 0,89851 \\
\hline Fonte: os autores. & &
\end{tabular}

O desvio padrão para todos os fatores foi abaixo de 1,0, ou seja, há evidências de que houve consonância nas respostas dos participantes desta pesquisa, isto é, uma baixa variabilidade nas respostas.

\subsection{ANÁLISE DA REGRESSÃO}

Os dados mostram que o modelo global de regressão para a variável dependente "eu me considero um consumidor ecologicamente correto" é estatisticamente significativo ( $\mathrm{F}=38,137$; $p$-value $=0,000)$, conforme a Tabela 2. E o poder de explicação ( $\mathrm{R}^{2}$ ajustado) desse modelo de regressão mostra que os fatores produto, hábitos domésticos, reciclagem e reutilização e consumo de energia explicam $41,4 \%$ da variável dependente "eu me considero um consumidor ecologicamente correto". O desvio padrão de 0,669 é baixo, contribuindo para mostrar a confiabilidade desse coeficiente de regressão. 
Tabela 2 - Resumo do modelo

\begin{tabular}{|c|c|c|c|c|c|c|c|c|c|c|}
\hline $\begin{array}{l}\text { Mo- } \\
\text { delo }\end{array}$ & $\mathbf{R}$ & $\begin{array}{l}\text { R qua- } \\
\text { drado }\end{array}$ & $\begin{array}{c}\text { R qua- } \\
\text { drado } \\
\text { ajus- } \\
\text { tado }\end{array}$ & $\begin{array}{c}\text { Erro } \\
\text { pa- } \\
\text { drão } \\
\text { da } \\
\text { esti- } \\
\text { mati- } \\
\text { va }\end{array}$ & $\begin{array}{c}\text { Alte- } \\
\text { ração } \\
\text { de R } \\
\text { qua- } \\
\text { drado }\end{array}$ & $\begin{array}{l}\text { Alte- } \\
\text { ração } \\
\quad \text { f }\end{array}$ & Df1 & Df2 & $\begin{array}{l}\text { Sig. } \\
\text { Alte- } \\
\text { ração } \\
\text { f }\end{array}$ & $\begin{array}{c}\text { Dur- } \\
\text { bin- } \\
\text {-Wat- } \\
\text { son }\end{array}$ \\
\hline 4 & $0,652 \mathrm{~d}$ & 0,425 & 0,414 & 0,669 & 0,016 & 5,906 & 1 & 206 & 0,016 & 1,952 \\
\hline
\end{tabular}

Fonte: os autores.

Nota: d: Preditores: (Constante), hábitos domésticos, produto, consumo de energia, reciclagem e reutilização.

e: Variável dependente: Y (Eu me considero um consumidor ecologicamente correto).

E os coeficientes de regressão $(0,265, p$-value $=0,000 ; 0,225, p$-value $=$ 0,$003 ; 0,172, p$-value $=0,016 ; 0,153, p$-value $=0,013$ ) que representam os fatores produto, hábitos domésticos, reciclagem e reutilização e consumo de energia, respectivamente, apresentam significância estatística, conforme a Tabela 3, ou seja, há evidências de relação positiva entre esses fatores. Em outras palavras, há evidências de que o tipo de produto adquirido, os hábitos domésticos, o consumo de energia e a reciclagem e reutilização de produtos afetam a consciência ecológica dos consumidores capixabas. Os demais fatores - ações de mudança e alimentação e saúde - não são estaticamente significativos.

Tabela 3 - Coeficientes para o modelo de regressão

\begin{tabular}{|c|c|c|c|c|c|c|c|}
\hline \multirow[b]{2}{*}{ Modelo 3} & \multicolumn{2}{|c|}{$\begin{array}{c}\text { Coeficientes não } \\
\text { padronizados }\end{array}$} & \multirow{2}{*}{$\begin{array}{c}\begin{array}{c}\text { Coefi- } \\
\text { cientes } \\
\text { padroni- } \\
\text { zados }\end{array} \\
\text { Beta }\end{array}$} & \multirow{2}{*}{$\mathbf{T}$} & \multirow{2}{*}{ Sig } & \multicolumn{2}{|c|}{$\begin{array}{l}\text { Estatísticas de } \\
\text { colinearidade }\end{array}$} \\
\hline & B & $\begin{array}{c}\text { Erro } \\
\text { padrão }\end{array}$ & & & & Tolerância & VIF \\
\hline Constante & $-0,159$ & 0,320 & & $-0,4906$ & 0,621 & & \\
\hline Produto & 0.301 & 0.081 & 0.265 & 3.736 & 0.000 & 0.556 & 1.799 \\
\hline $\begin{array}{l}\text { Hábitos do- } \\
\text { mésticos }\end{array}$ & 0.288 & 0.095 & 0.225 & 2.993 & 0.003 & 0.492 & 2.032 \\
\hline $\begin{array}{l}\text { Reciclagem e } \\
\text { reutilização }\end{array}$ & 0.167 & 0.069 & 0.172 & 2.430 & 0.016 & 0.557 & 1.794 \\
\hline $\begin{array}{l}\text { Consumo de } \\
\text { energia }\end{array}$ & 0.162 & 0.065 & 0.153 & 2.497 & 0.013 & 0.747 & 1.338 \\
\hline
\end{tabular}

Nota: a. Variável dependente: Y (Eu me considero um consumidor ecologicamente correto). 
Ainda na Tabela 3 os testes de tolerância (os valores estão bem acima de 0,10) e o Fator de Inflação de Variância (FIV) (os valores estão bem abaixo de 5,0) que medem o grau de colinearidade entre os quatro fatores (produto, hábitos domésticos, reciclagem e reutilização e consumo de energia) reforçam que esse modelo de regressão não apresenta problemas de multicolinearidade, conforme recomendado por Hair Junior et al. (2005).

E os resultados, conforme a Tabela 4, também mostram que aproximadamente 57\% (92,160/160,408 = 0,57) da variância total não são explicados por esse modelo de regressão. Isso pode ser entendido que ainda há outros fatores que podem ser considerados para entender melhor essa relação entre o nível de consciência ecológica e o comportamento dos consumidores capixabas.

Tabela 4 - Anova

\begin{tabular}{lrrrrr}
\hline \multicolumn{1}{c}{ Modelo 3 } & Soma dos quadrados & Df & Quadrado médio & Z & Sig. \\
\hline Regressão & 68,247 & 4 & 17,062 & 38,137 & $0,000 \mathrm{e}$ \\
Resíduo & 92,160 & 206 & 0,447 & & \\
Total & 160,408 & 210 & & & \\
\hline
\end{tabular}

Fonte: os autores.

Nota: a. Variável dependente: Y (Eu me considero um consumidor ecologicamente correto).

d. Preditores: (Constante), hábitos domésticos, produto, reciclagem e reutilização.

\subsection{ANÁLISE DE DIFERENÇAS ENTRE AS MÉDIAS DO COMPORTAMENTO ECOLOGICAMENTE CORRETO EM ALGUMAS VARIÁVEIS DEMOGRÁFICAS COM HOMENS E MULHERES}

\subsubsection{Teste Anova - Escolaridade}

As evidências mostram que as médias do comportamento ecologicamente correto entre as mulheres e os homens em relação à escolaridade das respondentes são estatisticamente significativas ao nível de $p$-value $=0,05$ para o fator reciclagem e reutilização, ou seja, quanto maior a escolaridade, maior o nível de consciência ecológica no que se refere à preocupação com o uso de materiais reciclados e que não agridem o meio ambiente, para ambos os gêneros.

Já o fator hábitos domésticos é estatisticamente significativo ao nível de $p$-value $=0,05$ somente para as mulheres, indicando que há diferenças entre as médias da escolaridade, isto é, quanto maior a escolaridade, mais dispostas elas estão em reci- 
clar o lixo e em consumir menos energia. O fator ação de mudança é estatisticamente significativo ao nível de $p$-value $=0,05$ somente para os homens, indicando que há diferenças entre as médias da escolaridade. Assim, quanto maior a escolaridade, maior a disposição em adotar um comportamento voltado para o uso de produtos e alimentos que respeitam o meio ambiente.

\subsubsection{Teste Anova - Idade}

As evidências indicam que as médias do comportamento ecologicamente correto em relação à idade entre as mulheres são estatisticamente significativas ao nível de $p$-value $=0,05$, para os fatores produto, reciclagem e reutilização e ação de mudança. Ou seja, quanto maior a idade, maior o nível de consciência ecológica quanto à preocupação com o uso de materiais reciclados e que não agridem o meio ambiente. Já para os homens, somente o fator ação de mudança foi estatisticamente significativo ao nível de $p$-value $=0,05$, isto é, quanto maior a idade dos homens, maior o nível de consciência ecológica no que diz respeito à preocupação com o uso de materiais que não agridem o meio ambiente.

\subsubsection{Teste Anova - Renda}

As evidências indicam que as médias do comportamento ecologicamente correto no que se refere à renda entre as mulheres e os homens não são estatisticamente significativas ao nível de $p$-value $=0,05$, para todos os fatores, ou seja, a renda não impacta a consciência ecologicamente correta desses consumidores.

\section{DISCUSSÃO DOS RESULTADOS}

As evidências mostram que os fatores consumo de energia, produto e hábitos domésticos impactam os comportamentos ecologicamente conscientes dos consumidores no momento de realização das compras e quanto aos seus hábitos, ou seja, aparentemente, os consumidores capixabas estão preocupados em adquirir produtos de empresas que respeitam o meio ambiente. Esses consumidores também procuram ter um comportamento que atribui alguma relevância aos produtos considerados verdes. As evidências também mostram que os demais fatores, ações de mudança, alimentação e saúde e reciclagem e reutilização apresentam movimento de tendência 
de que tais fatores podem começar a impactar os seus comportamentos ecologicamente conscientes. Esses achados pressupõem que há uma tendência de crescimento da consciência ecológica desses consumidores e que estão mais atentos às questões ambientais, sociais e suas consequências (LAI; CHENG, 2016; HOEK; ROLING; HOLDSWORTH, 2013; RETTIE; BURCHELL; RILEY, 2012). Essa tendência pode ser em decorrência do fato de a maioria dos respondentes da pesquisa (61\%) possuírem escolaridade de nível de pós-graduação. De fato, o nível de escolaridade impacta o comportamento ecologicamente correto desses consumidores, tanto para homens (ação de mudança) quanto para as mulheres (hábitos domésticos) e para o fator reciclagem e reutilização (ambos os gêneros). Quanto maior a escolaridade, maior a consciência ecológica em relação a esses fatores.

Além disso, a maioria (94\%) dos respondentes do estudo tem pelo menos 26 anos, mostrando que essas pessoas já estão maduras e possuem a capacidade de fazer escolhas. Neste estudo as evidências também mostram que quanto maior a idade dos homens e das mulheres, maior o nível de consciência ecológica no que diz respeito à mudança de hábitos voltados para o respeito com o meio ambiente. Para as mulheres, em particular, quanto maior a idade, maior a preocupação com o tipo de produto adquirido e com a reciclagem e reutilização de embalagens e materiais. Esses resultados estão coerentes com os estudos de vários pesquisadores, como Straughan e Roberts (1999), Portilho (2005), Dahlstrom (2012) e Ottman (2004), nos quais pedem a atenção para observar que os consumidores estão, cada vez mais, exigentes e conscientes, quando estão efetuando suas compras. Idade e escolaridade estão positivamente relacionadas ao comportamento de consumo ecologicamente consciente e à aquisição de produtos ecologicamente corretos. No que se refere à renda, embora aproximadamente $60 \%$ dos respondentes tenham renda acima de R\$ 4.510,00, não há diferenças significativas entre homens e mulheres.

Contudo, chama a atenção que esses consumidores estão neutros quanto ao impacto de produtos feitos de materiais reciclados ou mesmo que possam ser reciclados, ou ainda que utilizem embalagens biodegradáveis. Isso pode ser em razão do fato de que, em particular, na Cidade de Vitória, a coleta de lixo reciclável é muito baixa, cerca de 2\%. Nas outras cidades da Região Metropolitana da Grande Vitória, esse índice cai para menos de 0,5\%. E pouco mais da metade dos municípios do Estado do Espírito Santo assinaram os Termos de Compromisso Ambiental da coleta seletiva e de resíduos sólidos com o Ministério Público do Estado. Para que um condomínio residencial ou mesmo uma empresa possa implantar a coleta de lixo reciclável é necessário contratar os serviços de empresa especializada (ZANOTTI, 2013). Em 
Vitória, por mês, são 180 toneladas de materiais recicláveis recolhidas por meio da coleta seletiva em cerca de 150 postos de entrega voluntária (PEV), em 47 bairros (PREFEITURA DE VITÓRIA, 2016).

Diante do exposto e retomando o objetivo com a pesquisa - discutir os fatores que podem influenciar a consciência ecológica desses consumidores no momento em que estão realizando suas compras - curiosamente, as evidências mostram que o fator reciclagem e reutilização em conjunto com os fatores produto, hábitos domésticos e consumo de energia afetam a consciência ecológica desses consumidores. Apesar dessa discussão, quanto ao comportamento neutro sobre o descarte dos produtos, a preocupação em adquirir produtos que não agridem o meio ambiente, em reduzir o consumo de energia elétrica, em separar o lixo orgânico do lixo seco, fazem parte do modelo mental ecológico desses consumidores. Esses achados mostram que ações públicas voltadas à coleta reciclada de lixo podem ser bem-aceitas pela população do Estado do Espírito Santo.

Por outro lado, consumir lâmpadas mais caras, mas que economizam energia elétrica; deixar de usar produtos por razões ecológicas; deixar de comprar produtos e alimentos que podem causar a extinção de algumas espécies animais e vegetais ou que contenham agrotóxicos não impactaram a consciência ecológica desses consumidores. Ainda se percebe uma ambivalência dos consumidores que experimentam sentimentos e percepções opostas a respeito da adoção de um comportamento verde (CHANG, 2011).

Também é relevante considerar que a amostra deste estudo abrange o contexto do Estado do Espírito Santo, com uma inter-relação de circunstâncias econômicas, sociais e culturais distintas, por exemplo, de Porto Alegre (LAGES; VARGAS NETO, 2002), de São Paulo (ENOKI et al., 2008) e do contexto americano (STRAUGHAN; ROBERTS, 1999). Estudos realizados a respeito do comportamento do consumidor e sua consciência ambiental destacam a importância dos aspectos relacionados às crenças e aos valores presentes no ambiente em que tal consumidor está inserido. As obrigações ambientais apresentam uma série de fatores que necessitam ser observados como: o respeito por parte da sociedade com o meio ambiente na qual está inserido, o respeito às regulamentações jurídicas que protegem o meio ambiente, as diversidades culturais, a economia global e outros fatores não menos importantes, que precisam ser cumpridos por parte das sociedades físicas ou jurídicas (OTTMAN, 2004). 


\section{CONCLUSÃO}

Neste estudo teve-se como objetivo discutir os fatores que podem influenciar a consciência ecológica dos consumidores capixabas no momento em que estão realizando suas compras, ou seja, se esses consumidores estão tendo a preocupação em adquirir produtos, serviços, ideias e experiências ambientalmente corretos em consonância com hábitos ambientalmente responsáveis. Dessa forma, algumas reflexões emergem dessa discussão.

Primeiro, embora esses consumidores estejam em um processo de desenvolvimento de uma maior consciência ecológica, esse novo modelo mental tem implicado a adoção de um comportamento verde somente para alguns hábitos: compras de determinados produtos, serviços, ideias e experiências e hábitos domésticos de reciclagem e reutilização e de consumo de energia. Nesse sentido, é importante que todos os atores sociais - governos, organizações e sociedade em geral - envolvam-se para encorajar comportamentos voltados para um processo de compras e de assimilação de hábitos de produtos, serviços, ideias e experiências pró-ambientais e pró-sociais. Para tanto, esses atores precisam reaprender a lidar com essa nova realidade e a educação ambiental pode apoiar essa reorientação de atitudes e comportamentos, principalmente porque quanto maior a escolaridade e a idade, maior a consciência ecológica dos consumidores. A boa notícia para países como o Brasil, em particular, para o Estado do Espírito Santo, que tem disparidades sociais, é que a renda dos consumidores não impacta tal comportamento ecologicamente correto.

Segundo, não adiantam iniciativas voltadas para a mudança de comportamento se não houver a contrapartida de oferecer a esses consumidores infraestrutura necessária e suficiente para a concretização efetiva desses novos comportamentos. Por isso, em particular, os legisladores do Estado do Espírito Santo precisam se comprometer mais na promoção de comportamentos mais sustentáveis. Do contrário, as orientações estratégicas (ESPÍRITO SANTO..., 2015; 2018, p. 40) do Governo do Estado do Espírito Santo quanto “a uma mudança estrutural e comportamental de todos em relação aos recursos naturais e ao meio ambiente” podem não ser cumpridas.

Em terceiro lugar, as ações de marketing verde também precisam ser mais efetivas para apoiar e encorajar uma mudança de comportamento dos consumidores. As organizações também precisam rever suas posturas éticas e se reconstruírem em fundamentos sólidos de princípios e normas de fabricação e oferta de produtos, serviços, ideias e experiências com uma visão mais pró-ambiental e pró-social. Por último, todos os atores sociais - consumidores, organizações, Governo - ainda preci- 
sam se adaptar à dicotomia do atendimento aos seus desejos ilimitados com recursos limitados, mostrando que há uma longa caminhada para aumentar a consciência ecológica desses consumidores. A tendência mundial que cada vez mais se consolida é que os produtos adquiridos pelos consumidores necessitam se apresentar de forma ecologicamente correta.

Em relação às limitações, a amostra é não probabilística e por conveniência, por isso, atingiu-se um grupo de respondentes com elevada escolaridade e renda, podendo, em parte, enviesar os resultados desta pesquisa. Vale lembrar, todavia, que as evidências também mostraram que ainda há outros fatores que podem ser considerados para entender melhor essa relação entre consciência ecológica e comportamento desses consumidores capixabas. Sugere-se, portanto, estudar novos fatores que possam impactar a consciência ecológica de consumidores, as motivações intrínsecas e extrínsecas ao consumidor que podem influenciar tal comportamento, bem como as atitudes que o orientam. Assim, recomenda-se replicar a pesquisa em outros contextos que possuam microrregiões diferentes no que diz respeito à cultura, crenças, comportamentos sociais, renda e economia. Outra sugestão envolve a aplicação de estudo quantitativo a partir do referencial teórico já desenvolvido e também de entrevistas semiestruturadas.

\section{REFERÊNCIAS}

BEHSON, S. J. The relative contribution of formal and informal organizational work family support. Journal of Vocational Behavior, v. 66, i. 3, p. 487-500, 2005.

BELK, R. W.; DHOLAKIA, N; VENKATESH, A. The Shaping of consumption an market- ing institutions. In: BELK, R. W.; DHOLAKIA, N.; VENKATESH, A. (Ed.) Consumption and marketing, macro dimensions. Cincinnati, Ohio: South-Western Collegue Pushing, 1996.

BELZ, F. M.; PEATTIE, K. Sustainability marketing: a global perspective. Chichester: Wiley-VCH, 2009.

BENSON, J.; BROWN, M. Generations at work: are there differences and do they matter? The International Journal of Human Resource Management, v. 22, i. 9, p. 1843-1865, 2011. 
BRASIL. Lei n. 9.605, de 12 de fevereiro de 1998. Dispõe sobre as sanções penais e administrativas derivadas de condutas e atividades lesivas ao meio ambiente, e dá outras providências. Diário Oficial da União, Brasília, DF, 12 fev. 1998. Disponível em: <http://www.planalto.gov.br/ccivil_03/leis/L9605.htm>. Acesso em: 18 abr. 2016.

BUTZKE, I. C.; PEREIRA, G. R.; NOEBAUER, D. Sugestão de indicadores para avaliação do desempenho das atividades educativas do sistema de gestão ambiental - SGA da Universidade Regional de Blumenau - FURB. Revista Educação: Teoria e Prática, v. 9, n. 16, p. 1-13, 2001.

CHANG, C. Feeling ambivalent about going green. Journal of Advertising, v. 40, i. 4, p. 19-31, 2011.

CHEN, Y. S.; LAI, S. B.; WEN, C. T. The influence of green innovation performance on corporate advantage in Taiwan. Journal of Business Ethics, v. 67, i. 4, p. 331-339, 2006.

CHEN, Y. S. Towards green loyalty: driving from green perceived value, green satisfaction and green trust. Sustainable Development, v. 21, i. 5, p. 294-308, 2013.

COLTRO, A. Estímulos de Mercado às Ações Institucionais Socioambientais: Produtos Certificados - Inovação e Competitividade com Sustentabilidade. Revista Ciência e Administração, v. 13, n. 1, p. 85-89, ago. 2007.

DAHLSTROM, R. Gerenciamento de marketing verde. São Paulo: Cengage Learning, 2012.

DALMORO, M.; VENTURINI, J. C.; PEREIRA, B. A. D. Marketing verde: responsabilidade social e ambiental integradas na envolvente de marketing. Revista Brasileira de Gestão de Negócios, v. 11, n. 30, p. 38-52, 2009.

ENOKI, P. A. et al. Estratégias de marketing verde na percepção de compra dos consumidores na grande São Paulo. In: ENCONTRO DE MARKETING DA ASSOCIAÇÃO NACIONAL DE PÓS-GRADUAÇÃO E PESQUISA EM ADMINISTRAÇÃO, EMA, 3., 2008, Curitiba. Anais... Curitiba: ANPAD, 2008.

ESPÍRITO SANTO (Estado). Orientações Estratégicas 2015-2018. Disponível em: <http://www.planejamento.es.gov.br/planejamento/planejamento-estrategico/>. Acesso em: 06 abr. 2016. 
FUNDAÇÃO PROCON. A mudança de hábitos começa com todos nós. 2015. Disponível em: <http://www.procon.sp.gov.br/noticia.asp?id=4245>. Acesso em: 06 abr. 2016.

GARG, A. Green marketing for sustainable development: an industry perspective. Sustainable Development, v. 23, i. 5, p. 301-316, 2015.

HAIR JUNIOR, J. F. et al. Análise Multivariada de Dados. Porto Alegre: Bookman, 2005.

HOEK, J.; ROLING, N.; HOLDSWORTH, D. Ethical claims and labelling: An analysis of consumers beliefs and choice behaviours. Journal of Marketing Management, v. 29, i. 7, p. 772-792, 2013.

HOFFMANN, S.; SCHLICHT, J. The impact of different types of concernment on the consumption of organic food. International Journal of Consumer Studies, v. 37, i. 6, p. 625-633, 2013.

HUANG, M. H.; RUST, R. T. Sustainability and consumption. Journal of the Academy of Marketing Science, v. 39, i. 1, p. 40-54, 2011.

KOTLER, P. Reinventing Marketing to Manage the Environmental Imperative. Journal of Marketing, v. 75, i. 4, p. 132-135, July 2011.

LAGES, N. S.; VARGAS NETO, A. Mensurando a consciência ecológica do consumidor: um estudo realizado na cidade de Porto Alegre. In: ENCONTRO ANUAL DA ASSOCIAÇÃO BRASILEIRA DOS PROGRAMAS DE PÓS-GRADUAÇÃO EM ADMINISTRAÇÃO, 26., 2002. Anais... Salvador, 2002.

LAI, C. K. M.; CHENG, E. W. L. Green purchase behavior of undergraduate students in Hong Kong. The Social Science Journal, v. 53, i. 1, p. 67-76, 2016.

LEONIDOU, L. C.; LEONIDOU, C. N.; KVASOVA, O. Antecedents and outcomes of consumer environmentally friendly attitudes and behavior. Journal of Marketing Management, v. 26, i. 13, p. 1319-1344, 2010.

LIN, H. Y.; HSU, M. H. Using social cognitive theory to investigate green consumer behavior. Business Strategy and the Environment, v. 24, i. 5, p. 326-343, 2015.

LÓPES-RODRIGUEZ, S. Green marketing and a broader stakeholder orientation. Academy of Marketing Studies Journal, v. 20, i. 3, p. 14-25, 2016. 
LOPES, V. N.; PACAGNAN, M. N. Marketing verde e práticas socioambientais nas indústrias do Paraná. Revista de Administração, .v. 49, n. 1, p. 116-128, jan./fev./ mar. 2014.

MALHOTRA, N. K. Pesquisa de marketing: uma orientação aplicada. São Paulo: Bookman, 2006.

MINTON, E. et al. Sustainable marketing and social media a cross-country analysis of motives for sustainable behaviors. Journal of Advertising, v. 41, i. 4, p. 69-84, 2012.

OLIVEIRA, V. M.; CORREIA, S. N.; GÓMEZ, C. R. P. Escala de consumo sustentável: um estudo comparativo entre alunos e professores da Universidade Federal de Campina Grande - PB. Revista de Gestão Social e Ambiental, v. 8, n. 3, p. 89-105, 2014.

OTTMAN, J. A. Green marketing: opportunity for innovation. North Charleston: BookSurge Publishing, 2004.

PAÇO, A. et al. Conserving behaviour: a replication of the envirocon scale in four countries. APCBEE Procedia, Elsevier, v. 5, p. 44-49, 2013.

PEATTIE, K.; PEATTIE, S. Social marketing: A pathway to consumption reduction? Journal of Business Research, v. 62, i. 2, p. 260-268, 2009.

PEATTIE, K. Towards sustainability: the third age of green marketing. Marketing Review, v. 2, i. 2, p. 129-146, 2001.

POLONSKY, M. J. An Introduction To Green Marketing. Electronic Green Journal, v. 1, i. 2, p. 1-10, 1994.

POLONSKY, M. J. Transformative green marketing: Impediments and opportunities. Journal of Business Research, v. 64, i. 12, p. 1311-1319, 2011.

PORTILHO, F. Consumo sustentável: limites e possibilidades de ambientalização e politização das práticas de consumo. Cadernos EBAPE.BR, v. 3, n. 3, p. 1-12, 2005. 
PREFEITURA DE VITÓRIA (Município). Mais de 150 postos em 47 bairros recebem o lixo reciclável. 2016. Disponível em: <http://www.vitoria.es.gov.br/cidade/ mais-de-150-postos-em-47-bairros-recebem-o-lixo-reciclavel>. Acesso em: 18 abr. 2016.

PROTHERO, A. et al. Sustainable consumption: Opportunities for consumer research and public policy. Journal of Public Policy \& Marketing, v. 30, i. 1, p. 3138, 2011.

RETTIE, R.; BURCHELL, K.; BARNHAM, C. Social normalisation: Using marketing to make green normal. Journal of Consumer Behaviour, v. 13, i. 1, p. 9-17, 2014.

RETTIE, R.; BURCHELL, K.; RILEY, D. Normalising green behaviours: A new approach to sustainability marketing. Journal of Marketing Management, v. 28, i. 3, p. 420-444, Mar. 2012.

RICHEY JUNIOR., R. G. et al. The effects of environmental focus and program timing on green marketing performance and the moderating role of resource commitment. Industrial Marketing Management, v. 43, p. 1246-1257, 2014.

SACRAMENTO, S. R. V. et al. O efeito da consciência ecológica e do framing de perda e ganho no comportamento do consumidor. Revista de Administração da Unimep, v. 12, n. 3, p. 184-206, 2014.

SÃO PAULO (Estado). Decreto Municipal n. 55.827, de 06 de janeiro de 2015. Regulamenta a Lei n. 15.374, de 18 de maio de 2011, que dispõe sobre a proibição da distribuição gratuita ou venda de sacolas plásticas a consumidores em todos os estabelecimentos comerciais do Município de São Paulo. Diário Oficial, São Paulo, SP, 06 jan. 2015. Disponível em: <http://www3.prefeitura.sp.gov.br/cadlem/secretarias/ negocios_juridicos/cadlem/integra.asp?alt=07012015D\%20558270000>. Acesso em: 18 abr. 2016.

SÃO PAULO (Estado). Lei Municipal n. 15.374, de 18 de maio de 2011. Dispõe sobre a proibição da distribuição gratuita ou venda de sacolas plásticas a consumidores em todos os estabelecimentos comerciais do Município de São Paulo, e dá outras providências. Diário Oficial, São Paulo, SP, 18 maio 2011. Disponível em: <http:// www3.prefeitura.sp.gov.br/cadlem/secretarias/negocios_juridicos/cadlem/integra. asp?alt=19052011L\%20153740000>. Acesso em: 18 abr. 2016. 
STRAUGHAN, R. D.; ROBERTS, J. A. Environmental segmentation alternatives: a look at green consumer behavior in the new millennium. Journal of Consumer Marketing, v. 16, i. 6, p. 558-575, 1999.

VEIGA NETO, A. R. et al. Marketing verde aplicado à estratégia como prática: análise de variáveis na visão de Empreendedores. Revista Eletrônica do Mestrado em Administração da Universidade Potiguar - RAUnP, v. 6, n. 2, p. 23-37, 2014.

WELLS, V. K.; PONTING, C. A.; PEATTIE, K. Behavior and climate change: Consumer perceptions of responsibility. Journal of Marketing Management, v. 27, i. 7-8, p. 808-833, 2011.

YEH, T. A.; LAGE, J. A. Comportamento de consumo ecologicamente consciente: estudo comparativo Brasil x China. Caderno Profissional de Marketing - UNIMEP, v. 3, n. 2, p. 1-23, 2015.

YOUNG, W. et al. Sustainable consumption: green consumer behaviour when purchasing products. Sustainable Development, v. 18, i. 1, p. 20-31, 2010.

ZABKAR, V.; HOSTA, M. Willingness to act and environmentally conscious consumer behaviour: can prosocial status perceptions help overcome the gap? International Journal of Consumer Studies, v. 37, i. 3, p. 257-264, 2013.

ZANOTTI, D. Menos de 2\% do lixo em Vitória são recolhidos em coleta seletiva. Gazeta online, Vitória, 01 jun. 2013. Disponível em: <http://www.gazetaonline.com. br/_conteudo/2013/06/noticias/cidades/1448442-menos-de-2-do-lixo-em-vitoria-sao-recolhidos-em-coleta-seletiva.html>. Acesso em 18 abr. 2016.

ZHAO, H. H. et al. What affects green consumer behavior in China? A case study from Qingdao. Journal of Cleaner Production, v. 63, p. 143-151, 2014. 
APÊNDICE A - Questionário

\section{Produto}

Eu não compro produtos fabricados ou vendidos por empresas que prejudicam ou desrespeitam o meio ambiente.

Eu não compro produtos para minha casa que prejudicam o meio ambiente.

Quando eu tenho que escolher entre dois produtos iguais, eu sempre escolho o que é menos prejudicial às outras pessoas e ao meio ambiente.

Eu já convenci amigos ou parentes a não comprarem produtos que prejudicam o meio ambiente.

Eu sempre faço um esforço para reduzir o uso de produtos feitos de recursos naturais escassos.

Quando possível, eu sempre escolho produtos que causam menor poluição.

Eu procuro comprar produtos feitos de papel reciclado.

Sempre que possível, eu compro produtos feitos com material reciclado.

\section{Reciclagem e reutilização}

Eu procuro não comprar produtos que possuem grande quantidade de embalagens.

Eu tento comprar apenas produtos que podem ser reciclados.

Eu evito comprar produtos com embalagens que não são biodegradáveis.

\section{Hábitos domésticos}

Eu procuro, insistentemente, reduzir o consumo de energia elétrica.

Na minha residência eu separo o lixo orgânico do lixo seco.

Eu procuro comprar eletrodomésticos que consomem menos energia elétrica.

Sempre que possível, eu procuro comprar produtos com embalagens reutilizáveis.

\section{Ação de mudança}

Eu já troquei ou deixei de usar produtos por razões ecológicas.

Eu não compro produtos e alimentos que podem causar a extinção de algumas espécies animais e vegetais.

Quando eu conheço os possíveis danos que um produto pode causar eu não compro este produto.

\section{Consumo de energia}

Eu comprei lâmpadas mais caras, mas que economizam mais energia elétrica.

Eu troquei as lâmpadas da minha casa por lâmpadas de menor potência para reduzir o consumo de energia elétrica.

Eu me considero um consumidor ecologicamente correto.

Escala Likert: Discordo totalmente (1) Concordo totalmente (5). 
Como citar este artigo:

ABNT

HEMERLY, Leandro de Athayde; D’ANGELO, Marcia Juliana. Reflexões sobre o comportamento ecologicamente correto do consumidor capixaba. RACE, Revista de Administração, Contabilidade e Economia, Joaçaba: Ed. Unoesc, v. 16, n. 2, p. 655-680, maio/ago. 2017. Disponível em: <http://editora.unoesc.edu.br/index.php/ race>. Acesso em: dia/mês/ano.

APA

Hemerly, L. de A, \& D’Angelo, M. J. (2017). Reflexões sobre o comportamento ecologicamente correto do consumidor capixaba. RACE, Revista de Administração, Contabilidade e Economia, 16(2), 655-680. Recuperado em dia/mês/ano, de http:// editora.unoesc.edu.br/index.php/race 
